\title{
The association between haemospermia and severe hypertension
}

\author{
C.F. Close, W.W. Yeo and L.E. Ramsay
}

University Department of Medicine and Pharmacology, Royal Hallamshire Hospital, Sheffield S10 2JF, UK

\begin{abstract}
Summary: The association between haemospermia and hypertension was examined in a case-control study comparing 5 hypertensive patients with haemospermia to 20 age-matched hypertensive men. Patients with haemospermia had much higher blood pressures than hypertensive controls $(200 / 131 \mathrm{mmHg}$ vs $147 / 90 \mathrm{mmHg} ; P<0.0005 / P<0.0001)$, higher left ventricular voltage on ECG $(P<0.02)$, and higher concentrations of serum creatinine, proteinuria and renovascular disease (all $P=0.06$ vs controls). Haemospermia is associated with severe uncontrolled hypertension. It is not, however, associated with hypertension per se, as the prevalence of hypertension in published series of patients with haemospermia is no higher than that expected in the general population. Men presenting with haemospermia should have their blood pressure measured carefully as they may require antihypertensive treatment urgently.
\end{abstract}

\section{Introduction}

Haemospermia is usually encountered in urological practice and is commonly considered a minor disorder. The few published series have stressed the generally benign nature of the condition, ${ }^{1}$ and no cause can be found in a significant number of cases. Where there is a cause, inflammation and trauma are the predominant diagnoses. ${ }^{1,2}$ Three patients with haemospermia in association with severe hypertension have been reported. ${ }^{3,4}$ However, in three series of patients with haemospermia, ${ }^{1,2,5}$ totalling 177 cases, in whom hypertension was specifically sought, the prevalence of hypertension was only $2.8 \%$ ( $95 \% \mathrm{CI}$ $0-5.8 \%)$. This is quite unremarkable given the prevalence of hypertension in the general population, and suggests that any association of haemospermia is with severe hypertension, and not with hypertension per se. We have examined this hypothesis in a case-control study comparing 5 hypertensive patients with haemospermia to 20 matched hypertensive men who served as controls.

\section{Materials and methods}

We identified 5 hypertensive patients who complained of haemospermia while attending the Sheffield hypertension clinic by formal search of

Correspondence: C.F. Close, M.R.C.P., Diabetes and Endocrine Unit, Dudley Road Hospital, Birmingham B18 7QH, UK.

Accepted: 20 September 1990 the clinic records for the 3 years 1986-1988. Three of the five patients were receiving antihypertensive treatment with two or more drugs and the remaining two were on no medication when they reported haemospermia. Examination had revealed no local cause for haemospermia and culture of a midstream urine specimen was sterile in all cases. These patients $(n=5)$ were each matched for age (to the nearest decade) with four control patients $(n=20)$ who had attended the same clinic during the month that haemospermia was reported. The control patients were obtained by searching the clinic records in strict alphabetical order until the first 4 eligible patients were identified. Data were extracted from the clinic records for blood pressure, serum creatinine, left ventricular voltage on electrocardiogram (ECG), presence of proteinuria, and presence of renovascular disease. The blood pressure used for patients was that measured at the clinic visit when haemospermia was reported, and for controls the blood pressure measured at the clinic visit closest in time to this. The data for the two groups were compared using the MannWhitney test and Fisher's exact test.

\section{Results}

The features of patients with haemospermia and controls are shown in Table I. The groups were well matched for age, by design. Patients with haemospermia had much higher blood pressures than controls $(200 / 131 \mathrm{mmHg}$ vs $147 / 90 \mathrm{mmHg}$; $P<0.0005 / P<0.0001$ ), and had significantly 
Table I Clinical features of hypertensive patients with haemospermia compared to controls (mean and $\mathbf{9 5 \%}$ confidence intervals)

\begin{tabular}{lcc}
\hline & $\begin{array}{c}\text { Haemospermia } \\
(n=5)\end{array}$ & $\begin{array}{c}\text { Controls } \\
(n=20)\end{array}$ \\
\hline Age (years) & $46.2(36.9-55.5)$ & $47.5(43.0-53.0)$ \\
Systolic BP (mmHg) & $220(169-272)^{* *}$ & $147(139-156)$ \\
Diastolic BP (mmHg) & $131(121-141)^{* * *}$ & $90(85-94)$ \\
Serum creatinine $(\mu \mathrm{mol} / \mathrm{l})$ & $154(66-242)$ & $105(85-124)$ \\
ECG LV voltage $(\mathrm{mm})$ & $39.0(26.9-51.5)^{*}$ & $26.9(22.6-31.2)$ \\
\hline *Mann-Whitney U $\mathrm{U}=14.5, \quad P<0.02 ; \quad * *$ Mann-Whitney $\mathrm{U}=0$, \\
$P<0.0005 ;{ }^{* * *}$ Mann-Whitney U $=1, P<0.0001$.
\end{tabular}

higher left ventricular voltage on ECG $(P<0.02)$. They also had higher concentrations of serum creatinine (154 vs $105 \mu \mathrm{mol} / 1, P=0.06)$. Three of five patients with haemospermia had proteinuria and two had renovascular disease (both $P=0.06$ $v s$ controls). Only two control patients had proteinuria, and of these one had a raised serum creatinine. Two patients with haemospermia had accelerated-phase hypertension. In all 5 patients the haemospermia disappeared as the blood pressure came under control.

\section{Discussion}

Our study shows a clear association of haemospermia with uncontrolled severe hypertension, confirming previous uncontrolled observations. ${ }^{3,4}$ When compared to control patients with hypertension, those with haemospermia had strikingly higher blood pressures, averaging $220 / 131 \mathrm{mmHg}$. They also had higher left ventricular voltage on ECG, higher serum creatinine concentrations, and more had proteinuria. As in previous reports ${ }^{3,4}$ haemospermia resolved as the blood pressure came under control, although one cannot necessarily infer from this cause and effect. While hypertension is a recognized cause of haemospermia, its prevalence in three series of patients with haemospermia ${ }^{1,2,5}$ was only $2.8 \% \quad(95 \%$ CI $0-5.8 \%$ ), a percentage no higher than would be expected in the general population. When considered together with the findings of the present study, this leaves little doubt that the association of haemospermia is with uncontrolled severe hypertension, and not with hypertension per se.

Hypertension of the severity observed in our patients, averaging $220 / 131 \mathrm{mmHg}$, when haemo spermia was reported, needs to be treated as a matter of urgency. It is imperative that blood pressure is measured carefully in any patient presenting with haemospermia. If severe hypertension is found it can probably be accepted as a sufficient cause for the haemospermia without further investigation.

\section{References}

1. Fletcher, M.B., Herzberg, Z. \& Prior, J.P. The aetiology and investigation of haemospermia. Br J Urol 1981, 53: 669-671.

2. Yu, H.H., Wong, K.K., Lim, T.K. \& Leong, C.H. Clinical study of hemospermia. Urology 1977, 10: 562-563.

3. Iversen, P.S. Haemospermia and hypertension. Ugeskr Laeger 1987, 149: 596.

4. Hamburger, S., Styczynski, M., O'Hearne, J. \& German, G. Hemospermia and hypertension, two case reports. $J$ Kansas Med Soc 1980, 81: 459-460.

5. Ross, J.C. Haemospermia. Practitioner 1969, 203: 59-62. 